\title{
VARIATION OF THE EARTH TIDE-SEISMICITY COM- PLIANCE PARAMETER THE LAST 50 YEARS FOR THE SOUTH HIMALAIA FAULT, NEPAL
}

\author{
Contadakis M.E. ${ }^{1}$, Arabelos D.N. ${ }^{1}$, Vergos G. ${ }^{1}$, Scordilis E.M. ${ }^{2}$ and Spatalas S.D. ${ }^{1}$ \\ ${ }^{1}$ Department of Geodesy and Surveying, University of Thessaloniki, Greece \\ ${ }^{2}$ Department of Geophysics, Aristotle University of Thessaloniki, Greece
}

\begin{abstract}
Based on the results of our studies for the tidal triggering effect on the seismicity of the Hellenic area, we consider the confidence level of earthquake occurrence - tidal period accordance $p$ as an index of tectonic stress criticality for earthquake occurrence. In this paper, by the occasion of the recent catastrophic earthquake of Nepal, we investigate the variation of the index p for the South Himalaia Fault area. The preliminary results indicate positive correlation of the index $p$ with seismicity, for all the tidal periods. We suggest that this compliance parameter $p$ may be used as an additional element for the seismic risk assessment.
\end{abstract}

Keywords: Earthtides, Seismicity, Hi(stogram)Cum(ulation) method.

\section{Пєрí $\eta \psi \eta$}

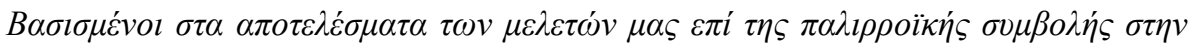



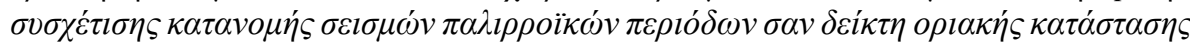

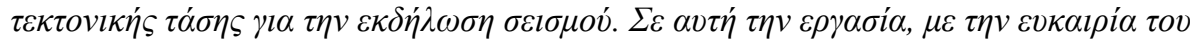

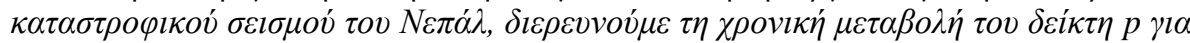

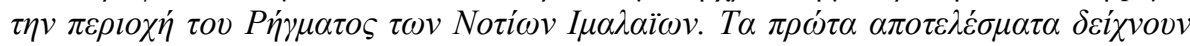

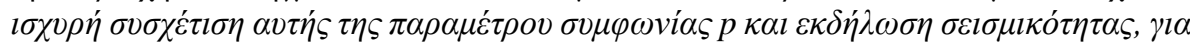

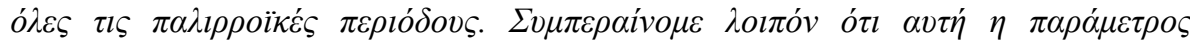

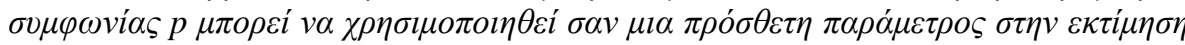

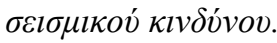

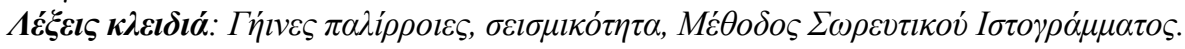

\section{Introduction}

Applying the Hi(stogram)Cum(ulation) method, which was introduced recently by Cadicheanu, van Ruymbecke and Zhu (2007), we analyze the series of the earthquakes occurred in the last 50 years in seismic active areas of Greece, i.e. the areas (a) of the Mygdonian Basin(Contadakis et al., 2007), (b) of the Ionian Islands (Contadakis et al., 2012), (c) of the Hellenic Arc (Vergos et al., 2012) and (d) Santorini (Contadakis et al., 2013; Contadakis et al., 2014). The result of the analysis for all the areas indicate that the monthly variation of the frequencies of earthquake occurrence is in accordance with the period of the tidal lunar monthly and semi-monthly (Mm and Mf) variations and the same happens with the corresponding daily variations of the frequencies of earthquake occurrence with the diurnal luni-solar (K1) and semidiurnal lunar (M2) tidal variations. In addition the confidence level for the identification of such period accordance between earthquakes occurrence frequency 
and tidal periods varies with seismic activity, i.e. the higher confidence level corresponds to periods with stronger seismic activity. These results are in favor of a tidal triggering process on earthquakes when the stress in the focal area is near the critical level. Based on these results, we consider the confidence level of earthquake occurrence - tidal period accordance, $p$, as an index of tectonic stress criticality for earthquake occurrence and we call it" Earth tide-seismicity compliance parameter". Then we check on posterior if the variation of the confidence level index, $p$, indicate the fault maturity in the case of the recent seismic activity at Fthiotida, and Evoikos Gulf, Greece. In this paper, by the occasion of the recent catastrophic earthquake of Nepal, we investigate the variation of the index $\mathrm{p}$ for the South Himalaia Fault area.

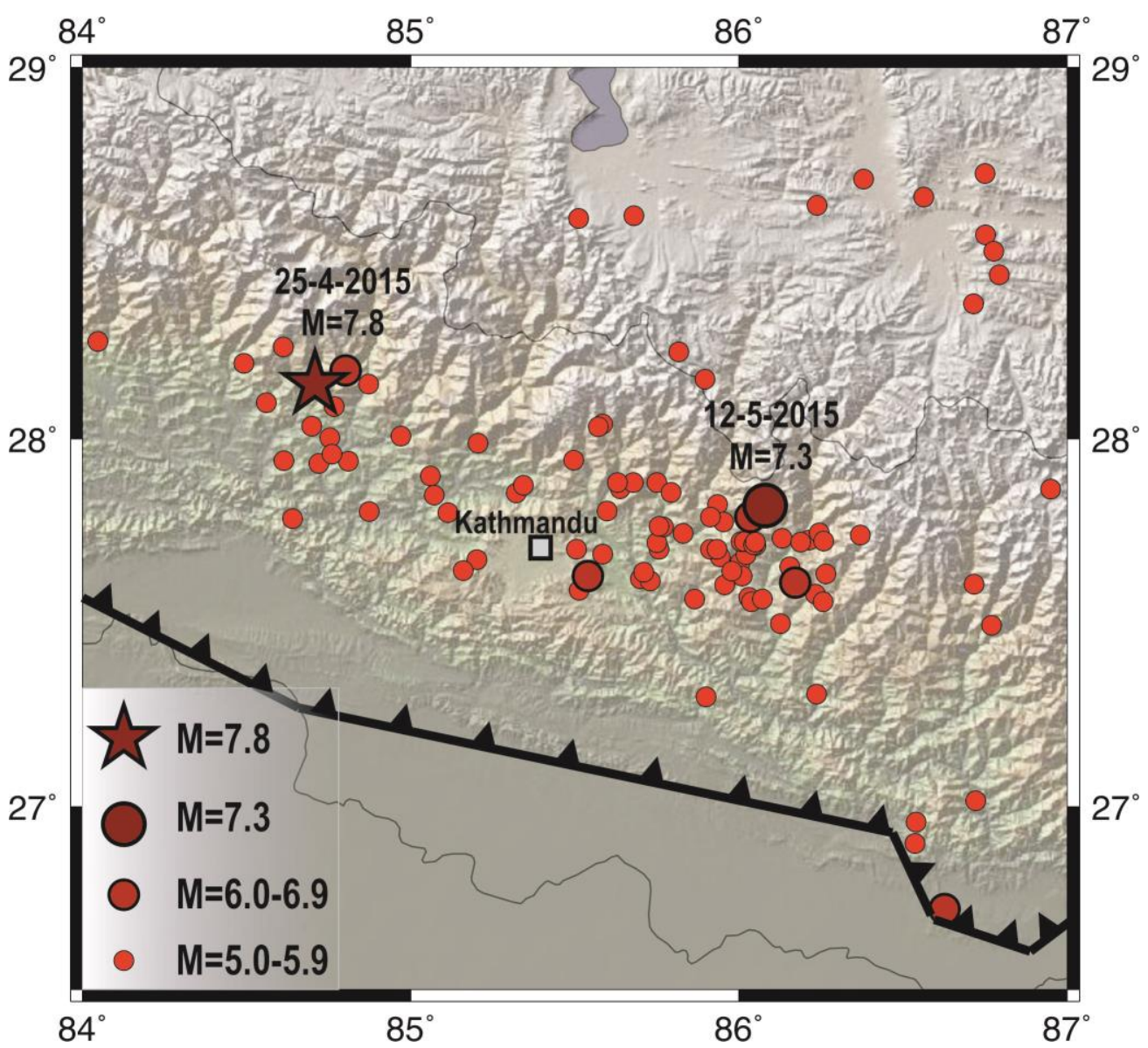

Figure 1 - Map of epicenters of all known earthquakes which occurred within the broader seismogenic region of the April 25 strong (M=7.8) Nepal earthquake since 1964. The thick black line represents the front of the collision between Indian (south) and Eurasian (north) plates.

\section{Seismotectonic Information}

On April 25, 2015 a strong earthquake of magnitude $\mathrm{M}=7.8$ occurred in Nepal with its epicenter located $\sim 80 \mathrm{~km}$ to the NW of the city of Kathmandu. The earthquake was followed by numerous aftershocks while 17 days later, on May 12, another strong earthquake of magnitude $M=7.3$ occurred about $140 \mathrm{~km}$ to the ESE of the April earthquake (Figure 1).

This seismic activity is connected with the continental collision which takes place between the Indian and Eurasian plates as a result of their convergence in a NNE direction at a rate of $\sim 4.5 \mathrm{~cm} / \mathrm{yr}$. 
Due to this convergence, the Indian plate underthrusts Eurasia resulting in the uplift of Himalayas and producing large earthquakes in the boundary region of these plates, mainly generated on thrust seismic faults striking in an almost EW direction.

The strongest known earthquake of the broader area occurred in 1934 with magnitude $\mathrm{M}=8.1$ about $270 \mathrm{~km}$ to the SE of the April 25 earthquake while in the same region occurred in 1988 the most recent strong event with $\mathrm{M}=6.8$.

In our analysis we use the earthquakes with $M \geq 4.0$ which occurred in the time period 1964 to $31 /$ $5 / 2015$ in the broader area of Nepal, confined by the coordinates $26.5^{\circ} \leq \varphi \leq 39.0^{\circ} \mathrm{N}, 84.0^{\circ} \leq \lambda \leq 87$. $0^{\circ}$.

Our sources are the catalogues of:

1) NCEDC (2015), Northern California Earthquake Data Center. UC Berkeley Seismological Laboratory Dataset. doi:10.7932/NCEDC, http://quake.geo.berkeley.edu/anss/catalog-search.html.

2) ISC (2015), International Seismological Centre, On-line Bulletin, Thatcham, United Kingdom, http://www.isc.ac.uk.

\section{Method of Analysis}

In order to check the possible correlation between Earth tides and earthquake occurrence we check the time of occurrence of each earthquake in relation to the sinusoidal variation of Earth tides and investigate the possible correlation of the time distribution of the earthquake events with Earth tides variation. Since the periods of the Earth tides component are very well known and quite accurately predictable in the local coordination system we assign a unique phase angle within the period of variation of a particular tidal component, for which the effect of earthquake triggering is under investigation, with the simple relation:

$\phi_{i}=\left\{\left[\frac{\left(t_{i}-t_{0}\right)}{T_{d}}\right]-\operatorname{int}\left[\frac{\left(t_{i}-t_{0}\right)}{T_{d}}\right]\right\} \times 360$

where $\phi_{i}=$ the phase angle of the time occurrence of the $i$ earthquake in degrees,

$t_{i}=$ the time of occurrence of the $i$ earthquake in Modified Julian Days (MJD),

$t_{o}=$ the epoch we have chosen in MJD,

$T_{d}=$ the period of the particular tidal component in Julian Days.

We choose as epoch $t_{o}$, i.e. as reference date, the time of the upper culmination in Kathmandu of the new moon of January 7, 1989 which has MJD $=47533.8947453704$. Thus the calculated phase angle for all the periods under study has 0 phase angle at the maximum of the corresponding tidal component (of course M2 and S2 has an upper culmination maximum every two cycles). As far as the monthly anomalistic moon concern the corresponding epoch $t_{o}$ is January 14, 1989 which has $\mathrm{MJD}=47541.28492$.

We separate the whole period in 12 bins of $30^{\circ}$ and stack every event according to its phase angle in the proper bin. Thus we construct a Cumulative Histogram of earthquake events for the tidal period under study.

A crucial point of this analysis is the use of a proper statistical test which will give us arguments to decide if such a result is correct or not i.e. will provide us a proper confidence level to our decision. To this purpose we use the well known Shuster's test (Shuster, 1897, see also Tanaka et al., 2002, 2006 and Cadicheanu et al., 2007). In Shuster's test, each earthquake is represented by a unit length vector in the direction of the assigned phase angle $\tilde{a}_{i .}$. The vectorial sum $D$ is defined as: 


$$
D^{2}=\left(\sum_{i=1}^{N} \cos a_{i}\right)^{2}+\left(\sum_{i=1}^{N} \sin a_{i}\right)^{2}
$$

where $N$ is the number of earthquakes. When $\alpha_{i}$ is distributed randomly, the probability to be the length of a vectorial sum equal or larger than $D$ is given by the equation:

$$
p=\exp \left(-D^{2} / N\right) \text {. }
$$

Thus, $p<5 \%$ represents the significance level at which the null hypothesis that the earthquakes occurred randomly with respect to the tidal phase is rejected. This means that the smaller the $p$ is the greater the confidence level of the results of the Cumulative Histograms is.

\section{Results}

In the present analysis we use the available earthquake catalogues which provide only the remarkable shocks i.e. earthquake with magnitudes greater than 4.0. Thus we consider the results of our analysis preliminary since the tidal triggering analysis demand the inclusion of any shock.

Table 1 - The earthquake frequency-tidal period compliance parameter $p$ for the respective decade.

\begin{tabular}{cccccccc}
\hline Decade & ShocksNo & Mmsyn & Mman & K1 & O1 & S2 & M2 \\
\hline $1970-80$ & 20 & 93.07 & 6.18 & 74.65 & 17.27 & 18.83 & 7.48 \\
$1980-90$ & 28 & 64.28 & 97.98 & 83.83 & 66.33 & 29.44 & 7.45 \\
$1990-00$ & 61 & 37.06 & 0.35 & 2.66 & 15.36 & 9.21 & 69.47 \\
$2000-10$ & 51 & 10.13 & 54.33 & 91.65 & 61.00 & 42.39 & 12.95 \\
$2010-15$ & 274 & 0,01 & 0.00 & 0.00 & 0.00 & 0.00 & 0.02 \\
\hline
\end{tabular}

Also the analysis will have very low time resolution since the time windows for the analysis should be large enough (ten years) in order to get statistically meaningful results. Nevertheless the results of our analysis justify our suggestions which were driven from our previous studies i.e. the confidence level of earthquake occurrence - tidal period accordance p depends on the seismicity or on the stress maturity of the fault for earthquake occurrence.

In fact, from the development of the seismicity at the South Homalaia Fault in the last 50 years it appears that the $63 \%$ of the notable shocks occurred in the last 5 years (Table, column 1). This indicates that the last 5 years is a seismic active period at the South Himalaia Fault. On the other hand, the Figures 2 to 7 , show the HistCum for all the shocks with $M \geq 4.0$, occurred within the last five years at the South Himalaia Fault, for all the main tidal periods. 


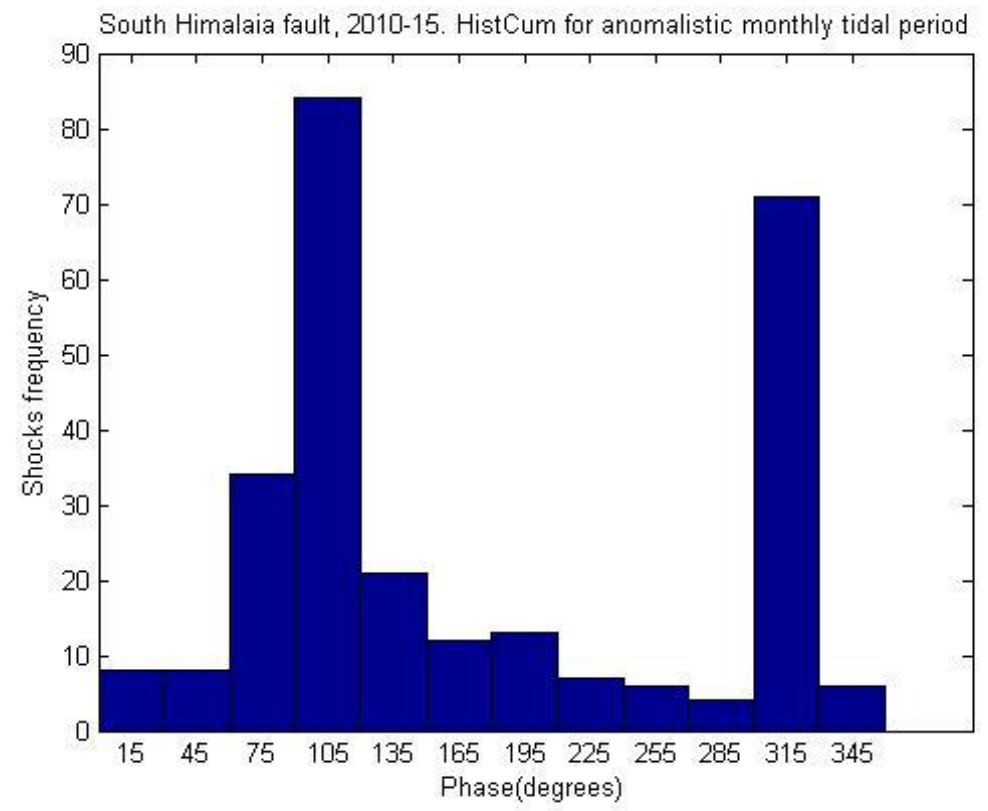

Figure 2 - South Himalaia Fault, 2010-15. HistCum for tidal anomalistic monthly period.

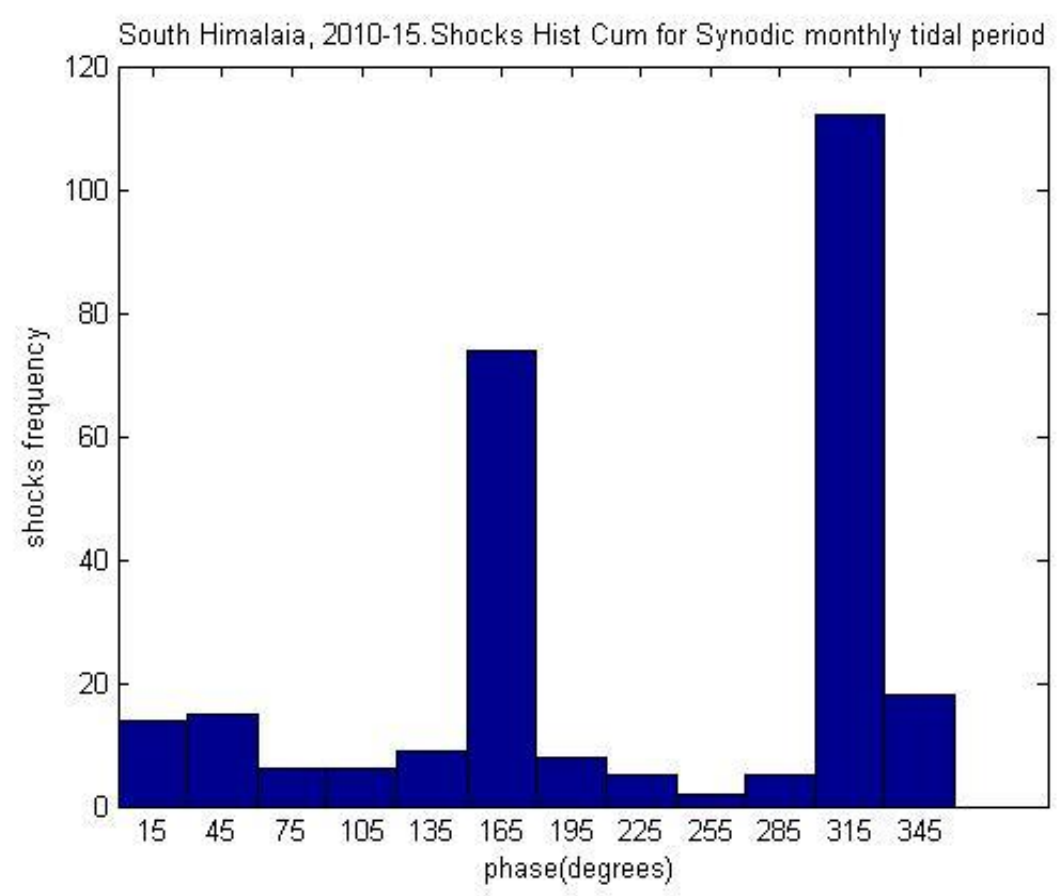

Figure 3 - South Himalaia Fault, 2010-15.HistCum for tidal synodic monthly period. 


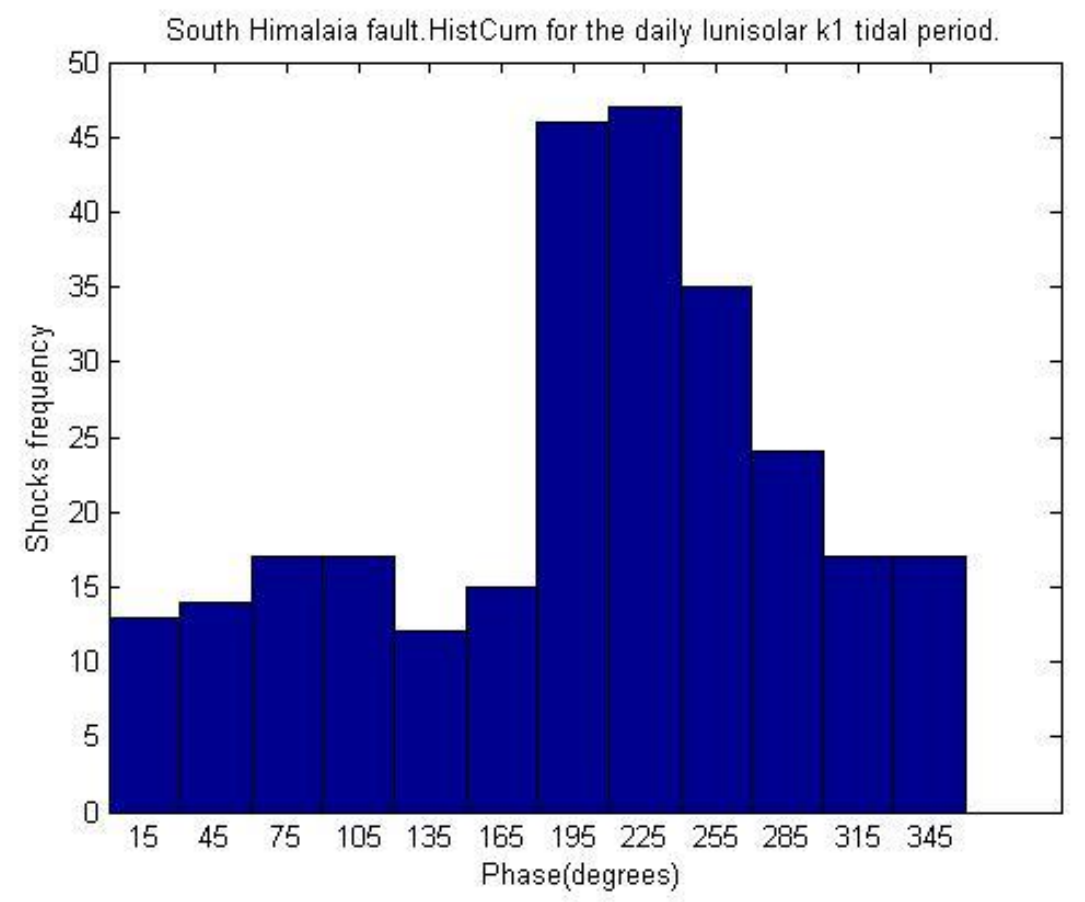

Figure 4 - South Himalaia Fault, 2010-15. HistCum for daily lunisolar tidal period K1.

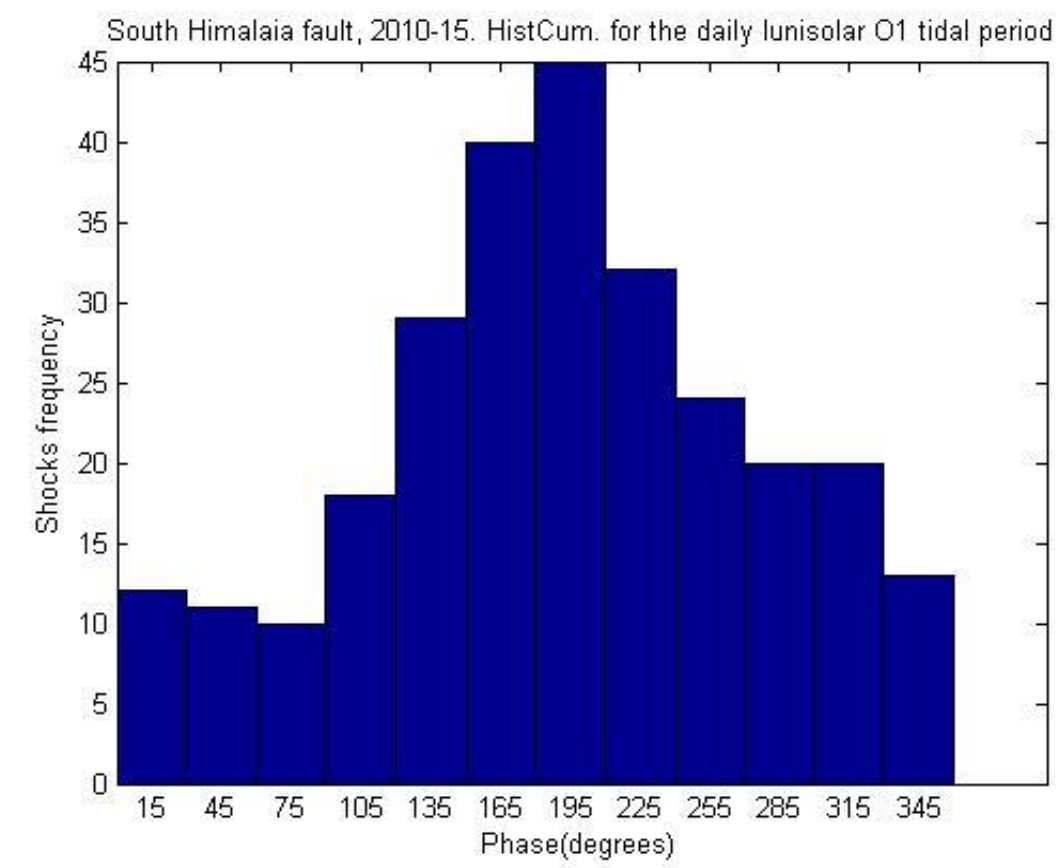

Figure 5 - South Himalaia Fault, 2010-15. HistCum for daily luni-solar tidal period 01. 


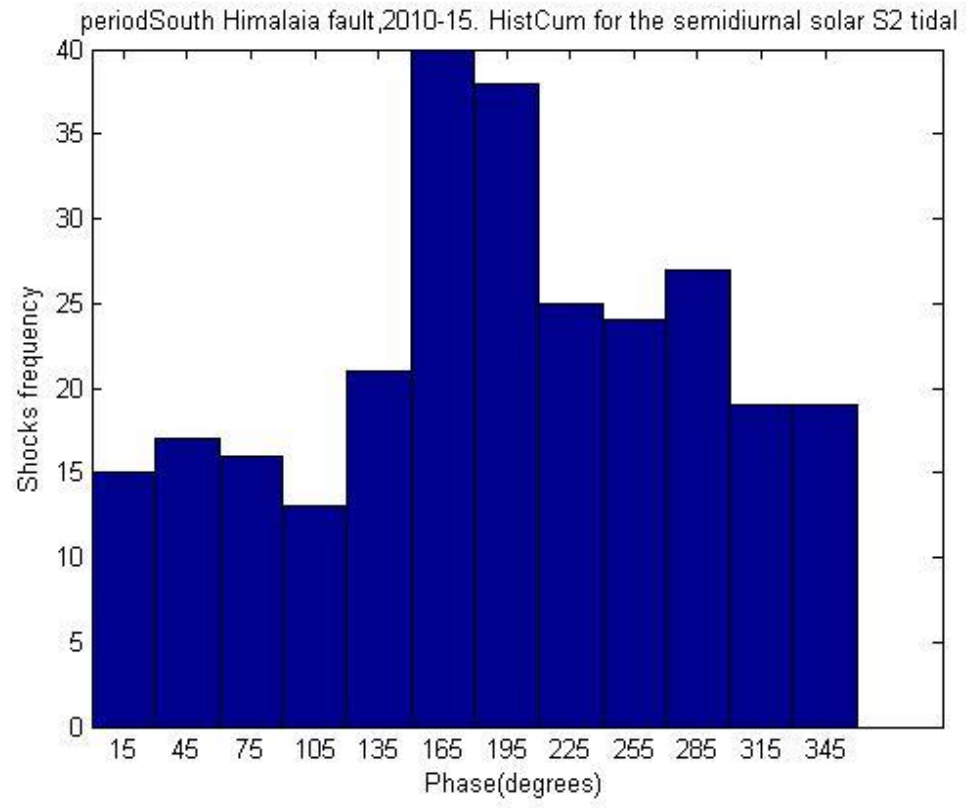

Figure 6 - South Himalaia Fault, 2010-15. HistCum for semidiurnal solar tidal period S2.

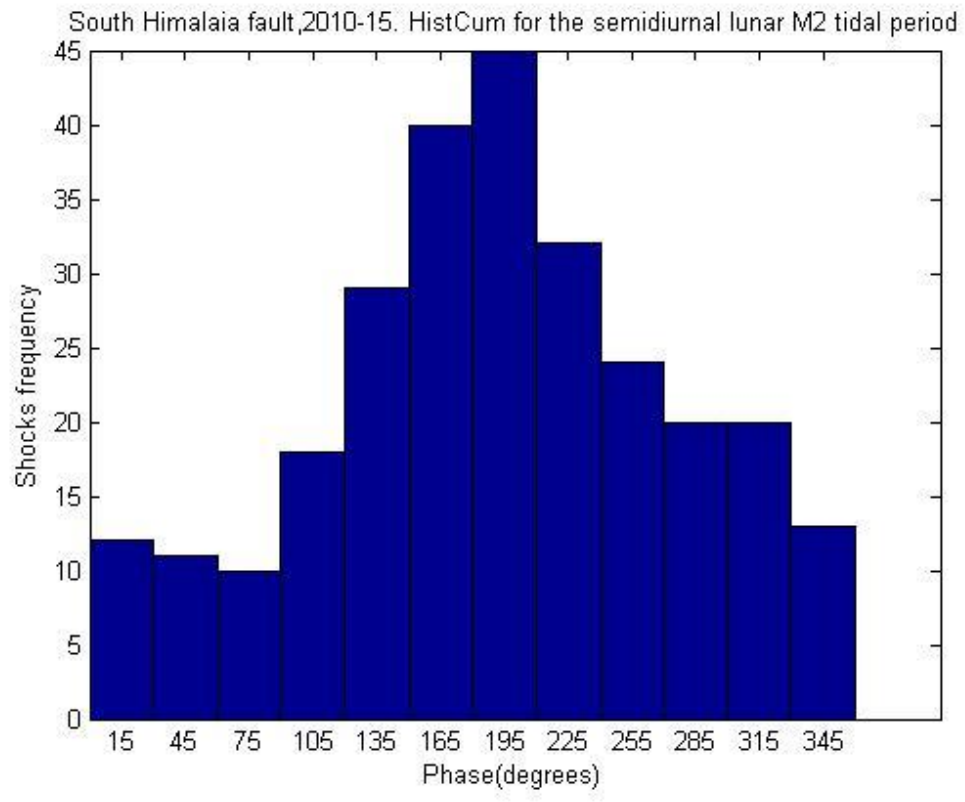

Figure 7 - South Himalaia Fault, 2010-15. HistCum for semidiurnal lunar tidal period M2.

It is seen that the monthly variation of the frequencies of earthquake occurrence are in perfect accordance with the period of the tidal lunar monthly variations (Synodic or Anomalistic) and the same happens with the corresponding daily variations of the frequencies of earthquake occurrence with the diurnal luni-solar (K1, O1 ) and semidiurnal solar or lunar (S2, M2) tidal variations. This is also is indicated from the last row of the Table. 


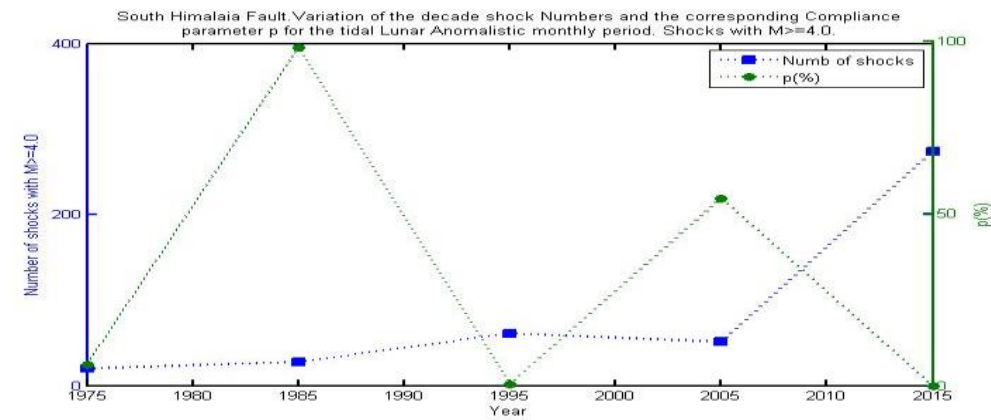

Figure 8 - South Himalaia Fault. The variation of the decade shock frequency and the corresponding Compliance parameter $\boldsymbol{p}$ for the Lunar tidal anomalistic monthly period.



Figure 9 - South Himalaia Fault. The variation of the decade shock frequency and the corresponding Compliance parameter $p$ for the Lunar tidal synodic monthly period.

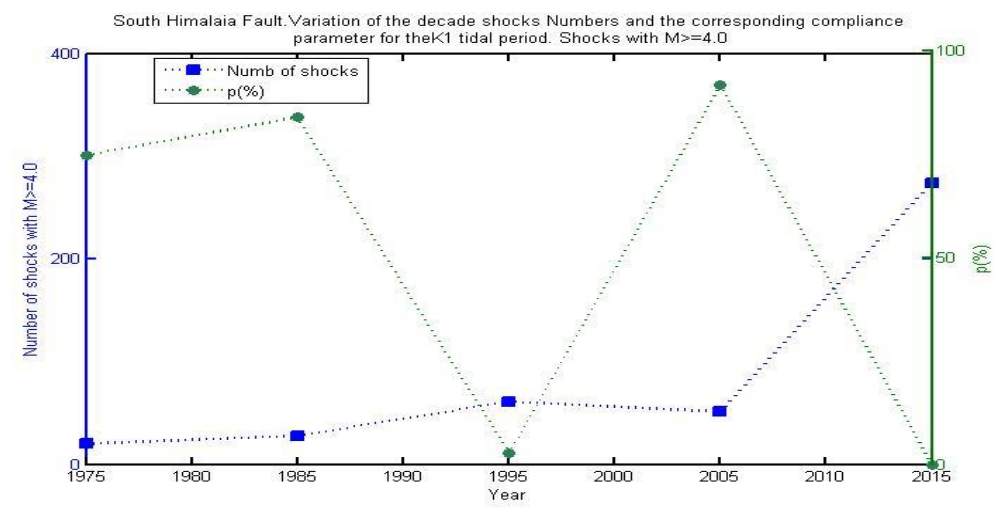

Figure 10 - South Himalaia Fault. The variation of the decade shock frequency and the corresponding Compliance parameter $\boldsymbol{p}$ for the daily luni-solar tidal period K1. 


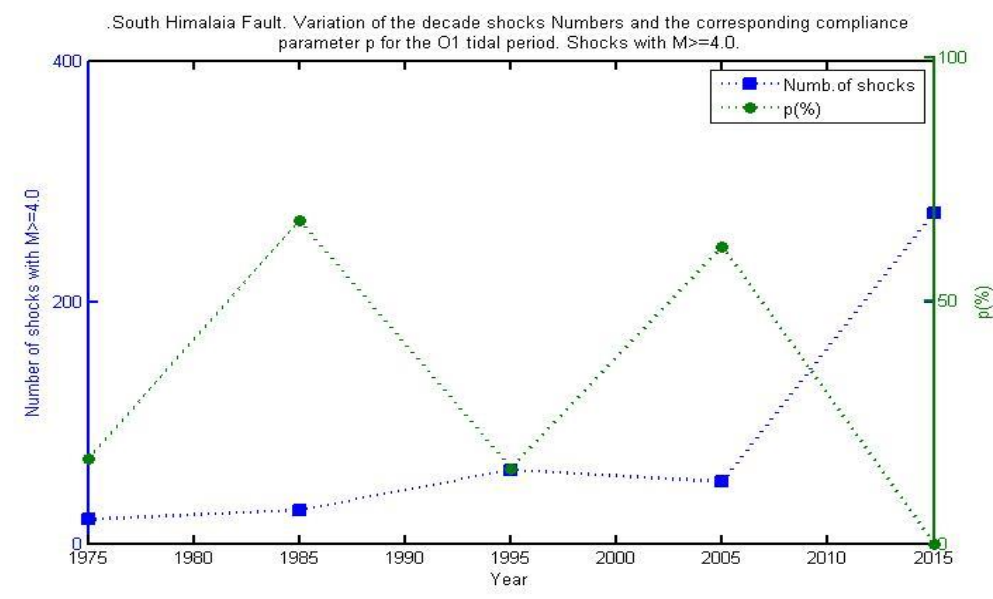

Figure 11 - South Himalaia Fault. The variation of the decade shock frequency and the corresponding Compliance parameter $\boldsymbol{p}$ for the daily luni-solar tidal period 01 .

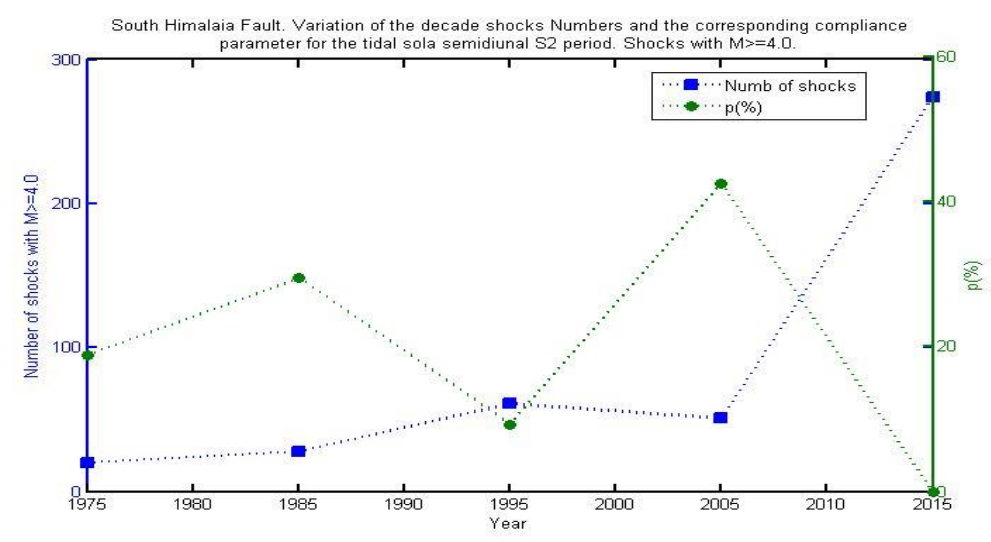

Figure 12 - South Himalaia Fault. The variation of the decade shock frequency and the corresponding Compliance parameter $\boldsymbol{p}$ for the semidiurnal solar tidal period S2.

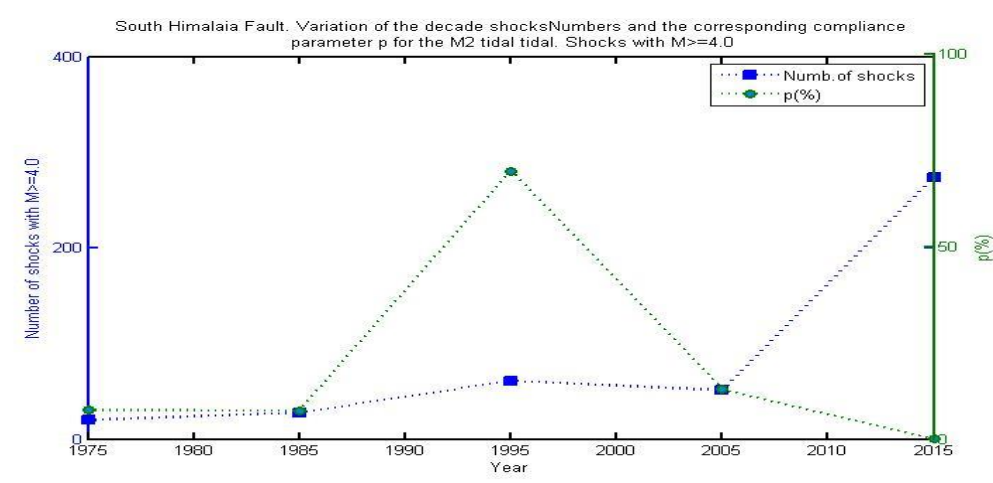

Figure 13 - South Himalaia Fault. The variation of the decade shock frequency and the corresponding Compliance parameter $\boldsymbol{p}$ for the semidiurnal lunar tidal period M2.

Finally the variation of the confidence level for the identification of such period accordance between earthquakes occurrence frequency and tidal periods, the so called compliance index $p$, is shown in Figures 8 to 13 and are given in table for all the tidal periods. It is seen that the compliance parameter 
$\mathrm{p}$ varies with seismic activity, i.e. the higher confidence level (smaller compliance parameter $p$ ) corresponds to periods with stronger seismic activity. These results are in favor of a tidal triggering process on earthquakes when the stress in the focal area is near the critical level.

\section{Conclusions}

The preliminary results of our investigation for the triggering effect, by the occasion of the recent $\mathrm{c}$ atastrophic earthquake of Nepal, for South Himalaia Fault area indicate positive correlation of the i ndex $\mathrm{p}$ with seismicity, for all the tidal periods. We suggest that this compliance parameter $\mathrm{p}$ may $\mathrm{b}$ e used as an additional element for the seismic risk assessment.

\section{References}

Arabelos, D., 2002. Comparison of Earth-tide parameters over a large latitude difference, Geophys. J. Int. (Research Note), 151, 950-956.

Arabelos, D.N., Asteriadis, G., Bloutsos, A., Contadakis, M.E. and Spatalas, S.D., 2008. Correlation between seismisity and barometric tidal exalting, Nat. Hazards Earth Syst. Sci., 8, 1129-1137.

Baker, T.F., 1984. Tidal determination of the Earth, Sci. Progr., Oxford, 69, 197-233.

Cadicheanu, N., van Ruymbeke, M. and Zhu, P., 2007. Tidal triggering evidence of intermediate depth earthquakes in Vrancea zone (Romania), NHESS, 7, 733-740.

Contadakis, M.E., Arabelos, D.N. and Spatalas, S., 2009. Evidence for tidal triggering on the shallow earthquakes of the seismic area of Mygdonia basin, North Greece. In: Terrestrial and Stellar Environment, Arabelos, D., Contadakis, M.E., Kaltsikis, C. and Tziavos, I., eds., Ziti Press Thessaloniki, Greece, 223-23 pp.

Contadakis, M.E., Arabelos, D.N. and Spatalas, S.D., 2012. Evidence for tidal triggering for the earthquakes of the Ionian geological zone, Greece, Annals of Geophysics, 55(1), 73-81.

Contadakis, M.E., Arabelos, D.N. and Vergos, G., 2013. Testing the recent Santorini seismic activity for possible tidal triggering effect, EGU General Assembly Conference Abstracts, 2013-8358.

Contadakis, M.E, Arabelos, D.N., Vergos, G. and Spatalas, S.D., 2015. Variation of the Earth tideseismicity compliance parameter the last 50 years for the seismic area of Evoikos, Greece, $E$ GU General Assembly Abstracts, 2015, 1443.

Contadakis, M.E, Arabelos, D.N., Vergos, G. and Spatalas, S.D., 2014. Variation of the Earth tideseismicity compliance parameter during the recent seismic activity of Fthiotida, Greece, $E G$ U General Assembly Abstracts, 2014, 1121.

Dehant, V., 1987, Tidal parameters for the inelastic Earth, Phys. Earth Planet Inter., 49, 97-116.

Dehant, V. and Zschau, J., 1989. The effect of mantle inelasticity on tidal gravity: a comparison between the spherical and the elliptical Earth model, Geophys. J., 97, 549-555.

Forough, S., 2005. Lithospheric structure of the Aegean obtained from P and S receivers, Chapter 2, Page 17, Dissertation der FU-Berlin, DDC 550.

Melchior, P., 1983. The Tides of the Planet Eath, Pergamon Press, New York.

Schuster, A., 1897. On lunar and solar periodicities of earthquakes, Proc. R. Soc. Lond., 61, 455465.

Tanaka, S., Ohtake, M. and Sato, H., 2002. Evidence for tidal triggering of earthquakes as revealed from statistical analysis of global data, J. Geophys. Res., 107(5B10), 2211.

Tanaka, S., Sato, H., Matsumura, S. and Ohtake, M., 2006. Tidal triggering of earthquakes in the subducting Philipine Sea plate beneath the locked zone of the plate interface in Tokai region, Japan, Tectonopysics, 417, 69-80.

Torge, W., 2001. Geodesy, $3^{\text {rd }}$ Edition, Walter de Gruyter, Berlin-New York.

Vergos, G., Arabelos, D.N. and Contadakis, M.E., 2012. Evidence for Tidal triggering on the earthquakes of the Hellenic Arc, Greece, Geoph. Res. Abs, 14, 2325. 